\title{
Dukungan Keluarga Untuk Meningkatkan Motivasi Pasien Kanker Payudara Menjalani Kemoterapi
}

\author{
Family Support To Increase Motivation Of Breast Cancer Patients \\ With Chemotherapy
}

\author{
Marlinda Marlinda $^{1 凶}$, Nur Fadhilah ${ }^{1}$, Novilia Novilia ${ }^{1}$ \\ ${ }^{1}$ Fakultas Kesehatan Universitas Muhammadiyah Pringsewu

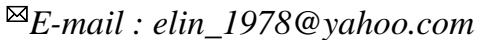

\begin{abstract}
Kata kunci:
Dukungan keluarga;

Motivasi;

Kanker paru dara;

Kemoterapi.
\end{abstract}

\section{Keyword:}

Family support;

Motivation;

Breast cancer;

Chemotherapy.

\begin{abstract}
Abstrak
Latar belakang: Peningkatan jumlah penderita kanker payudara mengalami trend peningkatan dari tahun ke tahaun di seluruh dunia, termasuk Indonesia.Salah satu pengobatan yang sering dilakukan adalah kemoterapi dengan berbagai efek samping yang penting mendapatkan perhatian. Tujuan:Penelitian ini bertujuan untuk mengetahui hubungan dukungan keluarga terhadap motivasi pasien kanker payudara dalam menjalani kemoterapi. Metode:Jenis penelitian ini adalah kuantitatif dengan desain studycross sectional. Jumlah sampel yang digunakan sebanyak 68 responden dengan teknik accidental sampling. Alat ukur yang digunakan adalah kuesioner untuk mengukur dukungan keluarga dan motivasi pasien. Analisis data bivariatmenggunakan uji chi-square. Hasil:Hasil penelitian menunjukkan terdapat hubungan yang signifikan antara dukungan keluarga terhadap motivasi pasien kanker payudara dalam menjalani kemoterapi ( $p$ value $=$ 0,000; OR=8,758). Simpulan: Dukungan keluarga meningkatkan motivasi pasien kanker payudara dalam menjalani selama kemoterapi untuk sembuh. Pentint upaya mengembangkan pelayanan kesehatan pada pasien kanker payudara dengan kemoterapi dalam peningkatan kualitas pelayanan, khususnya pemberian dukungan untuk memotivasi pasien yang menjalani kemoterapi dengan berbagai efek samping yang dihadapi.
\end{abstract}

\begin{abstract}
Background: The increasing prevalence of breast cancer is experiencing an increasing trend from year to year throughout the world, including Indonesia.. One treatment that is often done is chemotherapy with various important side effects that get attention. Purpose: This study aims to determine the relationship of family support to breast cancer patient motivation in undergoing chemotherapy. Method: This type of research is quantitative with cross sectional study design. The number of samples used was 68 respondents with accidental sampling technique. The measuring instrument used was a questionnaire to measure family support and patient motivation. Bivariate data analysis using chi-square test. Results: The results showed a significant relationship between family support for breast cancer patients' motivation in undergoing chemotherapy ( $p$ value $=0,000 ; O R=8,758$ ). Conclusion: Family support increases the motivation of breast cancer patients to undergo during chemotherapy. Efforts to develop health services in breast cancer patients with chemotherapy in improving the quality of service, especially providing support to motivate patients undergoing chemotherapy with various side effects encountered.
\end{abstract}

Copyright (C) 2019 Jurnal Kesehatan Metro Sai Wawai. All rights reserved. 


\section{Pendahuluan}

Kejadian kanker payudara di 140 dari 184 negara di seluruh dunia dengan angka kematian mencapai 522.000 pada tahun 2012 (American Cancer Society, 2015). Sedangkan, di Indonesia terjadi peningkatan jumlah penderita kanker di Indonesia dari 1,4 permil menjadi 1,8 permil (Kemenkes RI, 2018). Berdasarkan data Dinas Kesehatan Provinsi Lampung, penderita kanker yang rawat jalan dan rawat inap di Rumah Sakit di Provinsi Lampung selama tahun 2014 terdapat 383 kasus kanker leher rahim dan 1.119 kanker payudara (Saktiyanto, 2015).Pada tahun 2015 sampai tahun 2017 terjadi peningkatan jumlah penderita kanker payudara baik yang dirawat inap maupun rawat jalan di RS Urip Sumoharjo, pada tahun 2015 terdapat 1237 orang, tahun 2016 sebanyak 1178 orang dan tahun 2017 berjumlah 1717 orang (RS Urip Sumoharjo Bandar Lampung, 2017). Adapun tahun 2019 bulan Januari pasien kanker payudara yang terjadwal berkunjung sejumlah 162 orang pasien.

Kemoterapi merupakan salah satu pengobatan kanker payudara yang sering diberikan. Kemoterapi adalah proses pemberian obat - obatan anti kanker dalam bentuk pil cair atau kapsul atau melalui infus yang bertujuan membunuh sel kanker, tidak hanya sel kanker pada payudara, tetapi juga sel-sel yang ada diseluruh tubuh (Denton dalam Fauziana, 2011). Namun, kemoterapi ini dapat menimbulkan efek samping bagi penderita kanker payudara. Efek samping fisik kemoterapi yang umum adalah pasien akan mengalami mual dan muntah, perubahan rasa kecap, rambut rontok (alopesia), mukositis, dermatitis, keletihan, kulit menjadi kering bahkan kuku dan kulit bisa sampai menghitam, tidak nafsu makan, dan ngilu pada tulang (Setiawan, 2015; Nisman, 2011). Efek samping yang ditimbulkan membuat pasien kanker payudara merasa tidak nyaman, takut, cemas, malas, bahkan bisa sampai frustasi.

Pasien kanker payudara dengan kemoterapi sangat membutuhkan dukungan dari keluarga untuk meningkatkan motivasi untuk kesembuhannya. Karena Semua efek samping kemoterapi dapat dikalahkan dengan motivasi yang tinggi (Nisman, 2011; Setiawan, 2015). Dukungan keluarga merupakan bentuk perilaku melayani yang dilakukan keluarga, baik dalam dukungan emosional (perhatian, kasih sayang, empati), penghargaan (menghargai, umpan balik), instrumental (bantuan tenaga, dana, waktu), dan informasi (saran, nasehat, informasi) (Friedman, 2010). Sumber dukungan sosial yang utama dari keluarga, yaitu orang tua, pasangan dan saudara (Suyanto \& Arumdari, 2017; Purwanti, 2013). Selain itu, bentuk dukungan keluarga terhadap anggota keluarga adalah secara moral atau material. Adanya dukungan keluarga akan berdampak pada peningkatan rasa percaya diri pada penderita dalam menghadapi proses pengobatan penyakitnya (Misgiyanto \& Susilawati, 2014).

Penelitian Indriyatmo (2015) menginformasikan bahwa dukungan keluarga yang kurang pada pasien kanker dapat menyebabkan pasien tersebut kurang termotivasi menjalani kemoterapi sehingga enggan bahkan tidak datang sesuai jadwal yang telah ditentukan oleh dokter. Dukungan keluarga sangat memegang peranan penting dalam menyelesaikan masalah kesehatan dalam keluarga (Friedman, 2010). Dukungan yang diberikan keluarga dapat menumbuhkan rasa percaya diri dan meningkatkan motivasi pasien kanker payudara untuk menjalani kemoterapi. Hasil penelitian Sari, Dewi \& Utami (2012) menginformasikan bahwa pasien kanker payudara yang mendapatkan dukungan tinggi dari keluarga memiliki motivasi tinggi dalam menjalani kemoterapi. Didukung pula hasil penelitian Suyanto, et al (2017) yang menyebutkan bahwa perlunya dukungan keluarga untuk meningkatkan motivasi pasien kemoterapi untuk menjalani kehidupan di masyarakat.

Rumah Sakit Urip Sumoharjo merupakan salah satu rumah sakit yang memiliki fasilitas kemoterapi bagi penderita kanker payudara. Peneliti melihat adanya kecenderungan pasien yang tidak tertib dengan jadwal kemoterapi dan beberapa responden datang sendiri ke rumah sakit untuk kemoterapi. Belum pernah ada studi terkait motivasi pasien kanker payudara yang menjalani kemoterapi dan subjek penelitian diambil di ruang kemoterapi di RS Urip Sumoharjo. Penelitian sebelumnya hanya 
melihat mekanisme koping pasien dengan tingkat kecemasan pasien kemoterapi (Rahmawati, Lestari \& Setiawan, 2015) dan tidak spesifik pada kasus kanker payudara.

Berdasarkan Hasil studi pendahuluan pada bulan Januari 2019 di rumah sakit tersebut terdapat 20 penderita kanker payudara di unit kemoterapi diketahui bahwa seluruhnya berumur $>30$ tahun, 10 penderita kanker payudara yang menjalani kemoterapi, 4 orang mengatakan selalu termotivasi untuk sembuh dan mengikuti jadwal kemoterapi sesuai program. Terdapat 6 orang pasien mengatakan tidak menjalani kemoterapi secara rutin. Artikel ini merupakan publikasi dari penelitian yang bertujuan mengidentifikasi hubungan dukungan keluarga dengan motivasi pasien kanker payudara dalam menjalani kemoterapi di Rumah Sakit Urip Sumoharjo Bandar Lampung Tahun 2019.

\section{Metode}

Desain penelitian yang digunakan dalam penelitian ini adalah studi korelasi (correlation study) dengan menggunakan pendekatan cross sectional. Populasi 162 pasien kanker payudara bulan Januari tahun 2019 yang berkunjung di Ruang Kemoterapi Rumah Sakit Urip Sumoharjo. Besar sampel dalam berpartisipasi sejumlah 68 responden yang diambil menggunakan teknik accidental sampling. Penelitian ini menggunakan data primer, dengan instrumen penelitian berbentuk kuisioner dengan skala Likert. Kuisioner motivasi pasien dan dukungan keluarga menggunakan kuisioner yang pernah digunakan Indriyatmo (2015). Hasil pengukuran kedua instrumen terdiri dari 3 kategorik, yaitu kurang, cukup dan baik. Sebelum digunakan kuisioner dilakukan uji validitas dan reliabilitas pada 30 orang responden. Kuisioner dukungan keluarga didapat 22 pernyataan valid dari 25 pernyataan dan kuisioner motivasi didapat 18 pernyataan valid dari 20 pernyataan.

Setelah data terkumpul, hasil analisis didapat tidak ada yang memenuhi kriteria nilai cukup, maka hasil ukur penilaian dikategorik baik, jika skor 49-64 dan kurang jika skor 16-32 untuk variabel dukungan keluarga dan variabel motivasi pasien menjalani kemoterapi dikategorikan baik, bila skor $76 \%-100 \%$ dan kurang bila $<56 \%$ dari total skor. Analisis data membuktikan hubungan variabel independen dengan dependen menggunakan uji chi square, dengan menggunakan interval kepercayaan (CI) 95\% atau tingkat kesalahan 5\% dan odds ratio $>1$. Penelitian dilakukan setelah mendapatkan surat Lolos Kaji etik dari Komisi Etik Sekolah Tinggi Ilmu Kesehatan Muhammadiyah Pringsewu pada tanggal 16 Mei 2019 dengan Nomor: 058/KEPK/STIKesMPL/05/2019.

\section{Hasil penelitian}

\section{Karakteristik responden}

Karakteristik responden pada tabel 1 menunjukkan sebagian besar responden dalam kelompok lansia awal yaitu 33 orang (48.5\%), 26 orang (38.2\%) responden tidak bekerja, sementara lebih dari sebagian besar responden dengan pendidikan rendah yaitu 49 orang $(72.1 \%)$.

Tabel 1.

Distribusi frekuensi responden berdasarkan karakteristik usia, pekerjaan,dan pendidikan

\begin{tabular}{llcc}
\hline \multicolumn{1}{c}{ Karakteristik } & \multicolumn{1}{c}{ Kategori } & Frekuensi (n=68) & Persentase (n=100\%) \\
\hline Usia & Dewasa Akhir (38-45 tahun) & 9 & $13.2 \%$ \\
& Lansia Awal (46-55 tahun) & 33 & $48.5 \%$ \\
\multirow{3}{*}{ Pekerjaan } & Lansia Akhir (56-65 tahun) & 26 & $38.2 \%$ \\
& Tidak Bekerja & 26 & $38.2 \%$ \\
& Buruh & 11 & $16.2 \%$ \\
& Tani & 18 & $26.5 \%$ \\
& Wiraswasta & 6 & $8.8 \%$ \\
Pendidikan & PNS & 7 & $10.3 \%$ \\
& Rendah & 49 & $72.1 \%$ \\
& Menengah & 12 & $17.6 \%$ \\
& Tinggi & 7 & $10.3 \%$ \\
\hline
\end{tabular}




\section{Gambaran variabel penelitian}

\section{Dukungan keluarga dan motivasi kemoterapi}

Sebagian besar responden pada tabel 2 memiliki dukungan keluarga kurang (66.2\%) dan motivasi menjalani kemoterapi kategori kurang $(58,8 \%)$

Tabel 2.

Distribusi frekuensi responden berdasarkan dukungan keluarga dan motivasi kemoterapi pada penderita kanker payudara

\begin{tabular}{llcc}
\hline \multicolumn{1}{c}{ Variabel } & \multicolumn{1}{c}{ Kategori } & Jumlah $(\mathbf{n = 6 8})$ & Persentase $(\mathbf{n = 1 0 0 \% )}$ \\
\hline Dukungan Keluarga & Baik & 23 & $33.8 \%$ \\
\multirow{3}{*}{ Motivasi } & Kurang & 45 & $66.2 \%$ \\
& Baik & 28 & $41.2 \%$ \\
& Kurang & 40 & $58.8 \%$ \\
\hline
\end{tabular}

\section{Analisis bivariat}

Hasil analisis bivariat pada tabel 3 memperlihatkan bahwa dari 68 responden yang mendapat dukungan keluarga baik dengan motivasi baik yaitu 17 orang $(73,9 \%)$ dan responden yang mendapat dukungan keluarga baik dengan motivasi kurang yaitu 6 orang $(26,1 \%)$, sedangkan responden yang mendapat dukungan keluarga yang kurang dengan motivasi baik yaitu 11 orang $(24,4 \%)$ dan responden yang mendapat dukungan keluarga yang kurang dengan motivasi kurang yaitu 34 orang $(75,6 \%)$.

Hasil uji statistik dengan chi square $\left(X^{2}\right)$ menunjukkan ada hubungan antara dukungan keluarga terhadap motivasi pasien kanker payudara dalam menjalani kemoterapi $(p$-value $=0,000)$. Responden yang memiliki dukungan keluarga yang baik mempunyai risiko untuk memiliki motivasi yang baik dalam menjalani kemoterapi sejumlah 9 kali dibandingkan dengan pasien kanker payudara yang memiliki dukungan keluarga yang kurang ( $\mathrm{OR}=8.758$; CI 95\%: 2.766-27.729).

Tabel 3.

Hubungan Dukungan Keluarga Dengan Motivasi Pasien Kanker Payudara Dalam Menjalani Kemoterapi

\begin{tabular}{|c|c|c|c|c|c|c|c|c|}
\hline \multirow{3}{*}{ Dukungan Keluarga } & \multicolumn{4}{|c|}{ Motivasi } & \multicolumn{2}{|c|}{ Total } & \multirow{2}{*}{$p$-Value } & \multirow{2}{*}{$\begin{array}{c}\text { OR } \\
\text { CI 95\% }\end{array}$} \\
\hline & \multicolumn{2}{|c|}{ Baik } & \multicolumn{2}{|c|}{ Kurang } & & & & \\
\hline & $\mathbf{N}$ & $\%$ & $\mathbf{N}$ & $\%$ & $\mathbf{n}$ & $\%$ & \multirow{4}{*}{0.000} & \multirow{4}{*}{$\begin{array}{r}8.758 \\
(2.766- \\
27.729)\end{array}$} \\
\hline Baik & 17 & $73,9 \%$ & 6 & $26,1 \%$ & 23 & $100 \%$ & & \\
\hline Kurang & 11 & $24,4 \%$ & 34 & $75,6 \%$ & 45 & $100 \%$ & & \\
\hline Total & 28 & $41.2 \%$ & 40 & $58.8 \%$ & 68 & $100 \%$ & & \\
\hline
\end{tabular}

\section{Pembahasan}

\section{Dukungan keluarga}

Dukungan keluarga sangat diperlukan oleh pasien kanker payudara yang mendapatkan kemoterapi. Hasil analisis menunjukan sebagian besar responden kurang mendapatkan dukungan keluarga (66.2\%). Terlihat perbedaan dengan hasil penelitian Suyanto, et all (2017) didapat dukungan keluarga sebagian besar dalam kategorik sedang $(81,7 \%)$. Keluarga adalah dua orang atau lebih yang disatukan oleh kebersamaan dan kedekatan emosional serta yang mengidentifikasi dirinya sebagai bagian dari keluarga. Keluarga merupakan system pendukung utama yang memberikan perawatan langsung pada setiap keadaan sehat maupun sakit anggota keluarganya. Dukungan keluarga adalah bentuk perilaku melayani yang dilakukan keluarga, baik dalam dukungan emosional (perhatian, kasih sayang, empati), penghargaan (menghargai, umpan balik), instrumental (bantuan tenaga, dana, waktu), dan informasi (saran, nasehat, informasi) (Friedman, 2010). Responden merasa lebih nyaman ketika 
harus menjalani kemoterapi dan sangat terbantu dengan adanya keluarga mendampingi. Walaupun tidak bisa dipungkiri efek kemoterapi sangat menakutkan.

Dukungan dari keluarga merupakan suatu hal yang sangat penting bagi penderita kanker payudara dalam menjalani kemoterapi untuk dapat lebih memotivasi pasien dalam menjalani kemoterapinya, pasien merasa tetap ada yang memberikan perhatian, kasih sayang atau ada yang peduli kepadanya walaupun dalam keadaan sakit. Keterbatasan penelitian ini hanya menganalisis dari sudut pandang responden, sedangkan dari sudut pandang keluarga secara langsung dari ke-empat komponen dukungan keluarga belum diteliti. Sehingga, belum diketahui komponen yang sangat berhubungan dengan motivasi pasien kanker payudara menjalani kemoterapi.

\section{Motivasi pasien menjalani kemoterapi}

Motivasi merupakan variabel yang penting bagi seorang pasien kanker payudara yang diberikan kemoterapi. Hasil penelitian ini menunjukkan bahwa sebagian besar responden merasakan kurang mendapat motivasi dari keluarga (58.8\%), berbeda dengan hasil penelitian Sari, et al (2012) dimana didapat $(62,2 \%)$ memiliki motivasi tinggi. Motivasi sebagai keinginan yang terdapat pada diri seseorang individu yang mendorongnya untuk melakukan perbuatan-perbuatan, tindakan, tingkah laku atau perilaku. Motivasi dalam menjalani kemoterapi dipengaruhi oleh faktor internal dan eksternal. Faktor internal meliputi sifat kepribadian, pengetahuan, dan cita-cita, sedangkan faktor eksternal meliputi lingkungan, pendidikan, agama, sosial ekonomi, kebudayaan, dan keluarga. Dukungan keluarga merupakan faktor eksternal yang sangat penting bagi seseorang yang sedang menghadapi masalah dan dapat memotivasi orang tersebut dalam menjalani pengobatannya seperti pada pasien kanker payudara yang sedang menjalani kemoterapi (Subekti, 2010).

Hasil penelitian yang dilakukan oleh Indriyatmo (2015) menginformasikan bahwa dukungan keluarga yang kurang pada pasien kanker dapat menyebabkan pasien tersebut kurang termotivasi menjalani kemoterapi sehingga enggan bahkan tidak datang sesuai jadwal yang telah ditentukan oleh dokter. Perlunya motivasi keluarga dan orang terdekat kepada pasien selama menjalani kemoterapi untuk menumbuhkan rasa percaya diri dan meningkatkan motivasi pasien kanker payudara untuk menjalani kemoterapi, sehingga menjalankan program kemoterapi sampai selesai dan mencapai kesembuhan dari penyakitnya.

\section{Dukungan keluarga dan motivasi pasien menjalani kemoterapi}

Dukungan keluarga sebagai salah satu komponen yang mempengaruhi motivasi seorang pasien. Hasil penelitian memperlihatkan ada hubungan antara dukungan keluarga terhadap motivasi pasien kanker payudara dalam menjalani kemoterapi $(\mathrm{p}=0,000)$. Fenomena ini tampak bahwa ketika keluarga memberikan dukungan baik, maka akan berimplikasi terhadap motivasi pasien dalam menjalankan kemoterapi. Hasil analisis menemukan bahwa responden yang memiliki dukungan keluarga yang baik mempunyai risiko untuk memiliki motivasi yang baik dalam menjalani kemoterapi sejumlah 9 kali dibandingkan dengan pasien kanker payudara yang memiliki dukungan keluarga yang kurang (OR 8.758).

Hasil penelitian ini sejalan dengan pendapat Nursalam (2013) yang menjelaskan bahwa beberapa faktor yang mempengaruhi motivasi seseorang dalam menjalankan kemoterapi meliputi: faktor internal terdiri dari sifat kepribadian, intelegensi /pengetahuan, dan sikap. Faktor eksternal terdiri dari pengaruh lingkungan, pendidikan, agama, social ekonomi, kebudayaan, dukungan keluarga. Senada dengan penelitian Indriyatmo (2015), bahwa dukungan keluarga yang kurang pada pasien kanker dapat menyebabkan pasien tersebut kurang termotivasi menjalani kemoterapi, sehingga enggan bahkan tidak datang sesuai jadwal yang telah ditentukan oleh dokter. 
Dukungan keluarga sebagai sikap, tindakan penerimaan keluarga terhadap anggota keluarganya yang dapat diberikan dalam bentuk dukungan informasi, penilaian, intrumental dan emosional. Dukungan keluarga sangat memegang peranan penting dalam menyelesaikan masalah kesehatan dalam keluarga. Sumber dukungan keluarga dapat diperoleh dari orang tua, yang dianggap sudah pengalaman dalam banyak hal,sehingga apapun nasihat atau saran dari orangtua akan dilaksanakan. Selain itu, dukungan keluarga dapat juga diperoleh dari saudara yang merupakan orang terdekat dan akan secara langsung maupun tidak langsung berpengaruh pada motivasi untuk berperilaku (Friedman, 2010). Dukungan yang diberikan keluarga dapat menumbuhkan rasa percaya diri dan meningkatkan motivasi pasien kanker payudara untuk menjalani kemoterapi karena ingin cepat sembuh (Indriyatmo, 2015). Oleh karena itu diharapkan keluarga tetap mampu mempertahankan dan meningkatkan pemberian dukungan bagi anggota keluarga yang menjalani kemoterapi agar pasien memiliki motivasi tinggi dalam menjalani kemoterapi dan menjalani kehidupan di masyarakat.

Dukungan dalam bentuk informasi dapat diberikan dengan selalu memberikan informasi dari pihak keluarga dan senantiasa memberikan nasehat, solusi maupun pemberian informasi tentang kesehatan pasien yang diperoleh dari petugas kesehatan. Kemudian dukungan dalam bentuk penilaian merupakan peran keluarga dalam memberikan pemecahan masalah yang dialami oleh pasien serta keluarga memberikan dukungan untuk kesembuhan pasien (Friedman, 2010). Keluarga selalu memberi dorongan untuk melakukan kemoterapi secara teratur, memberikan penghargaan atau pujian atas usaha yang dilakukan pasien selama menjalani kemoterapi, tidak memaksakan apa yang tidak dikehendaki pasien, dan memberikan umpan balik mengenai hasil prestasinya akan memperkuat kepercayaan serta harga diri individu tersebut sehingga kualitas hidup dan motivasi pasien meningkat (Sari, Dewi \& Utami 2012; Suyanto \& Arumdari, 2017).

Selanjutnya dukungan dalam bentuk instrumental yang berasal dari keluarga dapat dilakukan dengan memberikan support finansial dalam pengobatan dan perawatan yang diterima oleh pasien serta selalu menyediakan obat yang dibutuhkan selama kemoterapi maupun dalam hal perawatan, dan dukungan dalam bentuk emosional dapat diberikan dalam bentuk pada pasien sehingga dapat membantu penguasaan emosional pasien kanker payudara. Keluarga memberikan dukungan emosional berupa empati, cinta dan kejujuran, dan mendengarkan semua keluhan dan tempat untuk mencurahkan semua perasaan yang dirasakan oleh pasien tentang pengobatan yang dijalani mampu mengurangi beban yang pasien rasakan. Sehingga, diharapkan kepada keluarga responden lebih banyak memberikan dorongan dan semangat kepada penderita kanker payudara yang menjalani kemoterapi baik dukungan informasional, dukungan penilaian/ penghargaan, dukungan instrumental, dukungan emosional, agar motivasi penderita semakin baik (Friedman, 2010; Indriyatmo, 2015)

Walaupun dari hasil penelitian ada beberapa responden yang kurang mendapat dukungan keluarga namun tetap memiliki motivasi baik untuk menjalani kemoterapi $(24,4 \%)$. Hal ini dapat terjadi karena ada faktor lain yang dapat meningkatkan motivasi pasien kanker payudara dalam menjalani kemoterapi, yaitu faktor spiritualitas. Seperti hasil penelitian Muslimawati (2017) tingkat spiritual berhubungan dengan motivasi pasien kanker menjalani kemoterapi. Penderita kanker akan memahami bahwa sakit adalah ujian dan cobaan dari Alloh Ta'aala bahwa setiap penyakit pasti ada obatnya serta penyakit yang dirasakan akan menghapus dosa-dosanya. Nabi Muhammad Shalallahu 'alahi wassalam bersabda: "Tidaklah Allah turunkan penyakit kecuali Allah turunkan pula obatnya" (HR. Muslim). "Tidaklah seorang muslim tertimpa suatu penyakit dan sejenisnya, melainkan Allah akan mengugurkan bersamanya dosa-dosanya seperti pohon yang mengugurkan daun-daunnya." (HR. Bukhari dan Muslim).

Keyakinan pasien akan ajaran dalam kutipan Al Hadist tersbut dapat menambahkan motivasi secara tindak langsung agar pasien menjalani pengobatan kemoterapi dengan baik dan benar agar ikhtiarnya membuahkan hasil yang maksimal. Selain faktor spiritualitas, dukungan dari teman sesama 
penderita kanker yang juga menjalani kemoterapi. Begitu juga dengan yang mendapatkan dukungan baik, belum tentu memiliki motivasi baik. Jika dalam dirinya sendiri tidak memiliki motivasi atau kemauan untuk sembuh dan ketidakyakinan diri terhadap Yang Maha Pencipta.

\section{Simpulan dan saran}

Pasien kanker payudara dengan kemoterapi sebagian besar masih merasakan dukungan dari keluarga kurang dan sebagian besar memiliki motivasi kurang untuk menjalani kemoterapi. Dukungan keluarga memberikan peningkatan motivasi yang baik bagi pasien kanker payudara dalam menjalani kemoterapi sesuai program pengobatan. Keluarga perlu meningkatkan selalu dukungan keluarga bagi responden dalam menjalani kemoterapi baik dukungan informasional, dukungan penilaian/ penghargaan, dukungan instrumental, dukungan emosional. Perawat dapat menggunakan sumbersumber lain sebagai motivasi bilamana responden kanker payudara tidak mendapatkan dukungan keluarga yang baik, agar responden tetap termotivasi untuk menjalani pengobatan kemoterapi

\section{Referensi}

American Cancer Society. (2015). Breast Cancer Facts \& Figures 2015-2016. Retrived November 29 ${ }^{\text {th }}, 2018$ from https://www.cancer.org/content/dam/cancer-org/research/cancer-facts-and-statistics/breastcancerfacts-and-figures/breast-cancer-facts-and-figures-2015-2016.pdf

Fauziana, A. (2011). Hubungan dukungan keluarga dengan motivasi menjalani kemoterapi pada pasien post op ca mammae di RS Kanker Dharmis Jakarta Barat.

Friedman, M. (2010). Buku ajar keperawatan keluarga, riset teori dan praktek. Edisi 5. Jakarta: EGC

Indriyatmo, W. 2015. Hubungan dukungan keluarga dengan motivasi untuk sembuh pada pasien kanker yang menjalani kemoterapi di Ruang One Day Care RSUD dr. Moewardi. Skripsi. Surakarta : STIKes Kusuma Husada Surakarta

Kementrian Kesehatan Republik Indonesia. (2018). Info Datin Kanker Payudara. Retreived November 29 ${ }^{\text {th }}, 2018$ from http://www.depkes.go.id/resources/download/pusdatin /infodatin /InfoDatin.pdf.

Misgiyanto \& Susilawati, D. (2014). Hubungan antara dukungan keluarga dengan tingkat kecemasan penderita kanker serviks. Jurnal Keperawatan,Vol. 5, Nomor 1, Januari 2014: 01-15.

Muslimawati, A. (2017). Hubungan spiritualitas dengan motivasi pasien kanker dalam menjalani kemoterapi Di RSUD Ulin Banjarmasin. Skripsi. Universitas Muhammadiyah Banjarmasin.

Nisman. (2011). Lima menit kenali payudara anda. Yogyakarta: CV Andi Offset

Purwanti. (2013). Hubungan dukungan keluarga dengan harga diri pada pasien kanker payudara di RSUD Panembahan Senopati Bantul. Skripsi. STIKes Aisiyah Yogyakarta. Retreived November $29^{\text {th }}, 2018$ from http://digilib.unisayogya.ac.id/553/1 /naskah\%20publikasi.pdf

Rahmawati, A., Lestari, A. dan Setiawan, F. (2015). Mekanisme koping berhubungan dengan tingkat kecemasan pasien kemoterapi Di Ruang Kemoterapi RS Urip Sumoharjo Lampung. Jurnal MOTORIK STIKesmukla. 10(20). Februari 2015.

RS Urip Sumoharjo. (2017). Medical Record RSUS tahun 2017.

Saktiyanto. 2015. Penderita kanker. Artikel Kesehatan Lampung. www.saibumi.com. Diakses pada tanggal 23 Maret 2019.

Sari, M., Dewi, Y. I., dan Utami, A. (2012). Hubungan dukungan keluarga terhadap motivasi pasien kanker payudara dalam menjalani kemoterapi di RuangCendrawasih I RSUD Arifin Achmad Provinsi Riau. Jurnal Keperawatan. PSIK STIKES Hangtuah Pekanbaru.

Setiawan. (2015). The effect of chemotherapy in cancer patient to anxiety. Majority, 4(4).

Subekti. (2010). Tingkat pengetahuan tentang kanker terhadap motivasi menjalani kemoterapi RSUP Dokter Kariadi Semarang. Jurnal Penelitian Kesehatan. 
Dukungan Keluarga untuk Meningkatkan Motivasi Pasien Kanker Payudara Menjalani Kemoterapi Marlinda, Nur Fadhilah, Novilia

Jurnal Kesehatan Metro Sai Wawai. 12 (2) 2019. E-ISSN2657-1390. P-ISSN19779-469X

Suyanto \& Arumdari, N.P.P. (2017). Dukungan keluarga pada pasien kanker yang menjalani kemoterapi di Rumah Sakit Islam Sultan Agung.Procceding Unissula Nursing Conference: Universitas Sultan Agung Semarang. 